\title{
NEW SYNONYMIES AND NEW COMBINATIONS FOR CHINESE ISSIDAE (HEMIPTERA: AUCHENORRHYNCHA: FULGOROIDEA)
}

\begin{abstract}
VlADIMIR M. GNEZDILOV
Zoological Institute, Russian Academy of Sciences, Universitetskaya Emb. 1, St. Petersburg 199034, Russia; E-mail:vmgnezdilov@mail.ru,vgnezdilov@zin.ru; https://orcid.org/0000-0002-7331-8744
\end{abstract}

Eight new synonymies of taxa of different rank and six new combinations are proposed in members of the family Issidae (Hemiptera: Auchenorrhyncha: Fulgoroidea) occurring in China based on their original descriptions. New synonymies (senior first): Hemisphaeriini Melichar, 1906 = Superciliarinae Meng, Qin et Wang, 2020, syn. n.; Pusulissus Bourgoin et Wang, 2020 = Flatiforma Meng, Qin et Wang, 2020, syn. n.; Tetrichina Chang et Chen, $2020=$ Lunatissus Meng, Qin et Wang, 2020, syn. n.; Microsarimodes Chang et Chen, $2019=$ Eusarimodes Meng, Qin et Wang, 2020, syn. n.; Rhombissus harimensis (Matsumura, 1913) $=R h$. brevispinus Che, Zhang et Wang, 2020, syn. n.; Celyphoma bifurca Meng et Wang, $2012=C$. gansua Chan, Zhang et Chang, 2014, syn. n.; Tetrichina fuscovinclum Wang et Bourgoin, 2020 = Lunatissus brevis Che, Zhang et Wang, 2020, syn. n.; T. trihamulata Chang et Chen, $2020=$ L. longus Che, Zhang et Wang, 2020, syn. n. New combinations: Pusulissus guizhouensis (Meng, Qin et Wang, 2020), comb. n.; P. menglaensis (Meng, Qin et Wang, 2020), comb. n.; P. ruiliensis (Che, Zhang et Wang, 2020), comb. n.; Microsarimodes maculosus (Che, Zhang et Wang, 2020), comb. n.; Kodaianella arcuata (Chang et Chen, 2020), comb. n.; K. trigona (Chang et Chen, 2020), comb. n.

Key words: Hemisphaeriini, Hysteropterinae, Issinae, Kodaianellini, Parahiraciini, Sarimini, new synonym, new combination, Oriental Region, Palaearctic Region, taxonomy.

\section{INTRODUCTION}

A series of papers and two monographs on the Chinese fauna of the family Issidae (Hemiptera: Auchenorrhyncha: Fulgoroidea), describing many new genera and species, were published during the past ten years, significantly contributing to the knowledge of Fulgoroidea of this country (MENG \& Wang 2012, Chen et al. 2014, Bourgoin \& Wang 2020, Chang et al. 2019, 2020a, $b$, WANG et al. 2020, Zhang et al. 2020). A careful analysis of these descriptions and illustrations, however, revealed several synonymies at subfamily, genus and species rank. The present paper aims to discuss these taxonomic problems propose new synonymies and new combinations for the involved taxa.

\section{MATERIAL AND METHODS}

The higher classification of the family Issidae follows GnezDilov et al. (2020). Morphological terminology follows Anufriev and Emeljanov (1988) and GNeZdilov et al. (2014). 


\section{TAXONOMY}

Family Issidae Spinola, 1839

Subfamily Issinae Spinola, 1839

Tribe Hemisphaeriini Melichar, 1906

Hemisphaeridae Melichar, 1906: 3. Type genus: Hemisphaerius Schaum, 1850, by subsequent designation.

Superciliarinae Meng, Qin et Wang in Zhang et al. 2020: 296, syn. n. Type genus: Superciliaris Meng, Qin et Wang, 2020, by original designation.

Notes. A close relationship of Hemisphaeriinae sensu Zhang et al. (2020) and Superciliarinae is indicated by the hemisphaerical forewings possessing a reticulate venation, and particularly the evident similarity of the penis, style, and male anal tube in these two groups. The only differences between the two purported subfamilies are apparently the relative width of the head and the pronotum and the width of genae (ZHANG et al. 2020, p. 559), which are hardly of subfamily level significance and not a constant character among various hemisphaeriine taxa. The reticulate venation of Superciliaris (the single genus included in Superciliarinae) suggests a close relationship to the hemisphaeriine genus Eusudasina Yang, 1994, while the peculiar triangular subapical processes of the dorsolateral lobes of the phallobase and the lack of neck or short neck of the style of Superciliaris are potential synapomorphies shared with the hemisphaeriine genus Epyhemisphaerius Chan et Yang, 1994 (CHAN \& YANG 1994, GNEZDILOv 2018: figs. 27-31, sp). There seems to be no evidence supporting the removal of Superciliaris from Hemisphaeriinae and its placement into a subfamily of its own. Accordingly, Superciliarinae is hereby downgraded to a junior subjective synonym of Hemisphaeriini sensu GNEzDiLov et al. (2020).

\section{Tribe Kodaianellini Wang, Zhang et Bourgoin, 2016}

\section{Genus Kodaianella Fennah, 1956}

Kodaianella Fennah, 1956: 508. Type species: Kodaianella bicinctifrons Fennah, 1956, by original designation.

Notes. The two species listed below are transferred into the genus Kodaianella based on the 3-lobed hind wings with developed vannus and anal lobe, the presence of peculiar elongately triangular or spine-shaped processes of the dorsolateral lobes of the phallobase and the style possessing a strong process under the capitulum. The currently monotypic genus Sivaloka Distant, 1906, characterized by the rudimentary vannus and reduced anal lobe of the hind wing, is apparently endemic to India (GNezDilov 2013). 
Kodaianella arcuata (Chang et Chen, 2020), comb. n.

Sivaloka arcuata Chang et Chen in CHANG et al. 2020a: 96, figs 29-43.

Kodaianella trigona (Chang et Chen, 2020), comb. n.

Sivaloka trigona Chang et Chen in CHANG et al. 2020a: 100, figs 44-55.

Tribe Parahiraciini Cheng et Yang, 1991

Genus Pusulissus Bourgoin et Wang, 2020

Pusulissus Bourgoin et Wang, 2020: 73. Type species: Pusulissus phiaoacensis Bourgoin et Wang, 2020, by original designation.

Flatiforma Meng, Qin et Wang in ZHANG et al. 2020: 353, syn. n. Type species: Flatiforma guizhouensis Meng, Qin et Wang, 2020, by original designation.

Notes. The original descriptions and illustrations of the habitus and male genitalia leave no doubt about the synonymy of these two genera. The genus is characterized by its relatively wide body in dorsal view, an elongate metope, with only median carina being distinct and with lateral tubercles, a transverse coryphe, the forewing with $\mathrm{R} 2 \mathrm{M} 4 \mathrm{CuA} 1$, the male anal tube being wide in dorsal view, with its lateral margins corner-shaped and turned down, the dorsolateral lobes of the phallobase lacking processes, the ventral phallobase lobe bearing a small pointed process medially, and the ventral aedeagal hooks being strongly curved.

The date of publication of the work of Bourgorn et WANG (2020) is indicated on the first page of the article as 25th November, 2020. The copyright page on the verso of the title page of ZHANG et al. (2020) gives the date of publication as November 2020; Y. ZHANG (pers. comm.) informed me that the book was published on 26th of November, 2020. Thus, Pusulissus has priority over Flatiforma.

Pusulissus guizhouensis (Meng, Qin et Wang, 2020), comb. n. Flatiforma guizhouensis Meng, Qin et Wang in Zhang et al. 2020: 354, fig. 140, pl. 27 a-c.

Notes. This species is very close to P. coronomensis Bourgoin et Wang, 2020 according to the structure of its male genitalia, but it is well distinguished from the latter species by the sternite VII of the female, which possesses a median process. These species were described from neighbouring administrative regions (Guangxi and Guizhou) in southern China (Bourgoin \& WANG 2020, ZHANG et al. 2020). 
Pusulissus menglaensis (Che, Zhang et Wang, 2020), comb. $\mathrm{n}$. Flatiforma menglaensis Che, Zhang et Wang in ZHANg et al. 2020: 355, fig. 141, pl. 27 d-f.

Pusulissus ruiliensis (Che, Zhang et Wang, 2020), comb. n. Flatiforma ruiliensis Che, Zhang et Wang in ZHANG et al. 2020: 357, fig. 142, pl. 27 g-i.

\section{Genus Rhombissus Gnezdilov et Hayashi, 2016}

Rhombissus Gnezdilov et Hayashi, 2016: 47. Type species: Issus harimensis Matsumura, 1913, by original designation.

\section{Rhombissus harimensis (Matsumura, 1913)}

Issus harimensis Matsumura, 1913: 61.

Rhombissus brevispinus Che, Zhang et Wang in Zhang et al. 2020: 359, fig. 143, pl. 27 j-1, syn. n.

Notes. All important features of the peculiar male genitalia of $R h$. harimensis, with an anal tube turned downwards apically, ventral aedeagal hooks with short upper processes, and ventral phallobase lobe with small apical concavity (GNEZDILOv \& HaYAshi 2016: figs 1-4) are readily recognizable in the illustrations accompanying the original description of $R h$. brevispinus. The fact ZHANG et al. (2020) did not compare their new species with the evidently very closely related $R h$. harimaensis suggests that they likely overlooked this species. Therefore, there is no reason to treat the Chinese continental population as a species distinct from the one occurring in the Japanese Islands, even if the latter population is characterized by a somewhat larger size which might be due to island isolation. The synonymy of these two names is accordingly proposed.

\section{Tribe Sarimini Wang, Zhang et Bourgoin, 2016}

\section{Genus Tetrichina Chang et Chen, 2020}

Tetrichina Chang et Chen in CHANg et al. 2020b: 39. Type species: Tetrichina trihamulata Chang et Chen, 2020, by original designation.

Lunatissus Meng, Qin et Wang in Zhang et al. 2020: 496, syn. n. Type species: Lunatissus brevis Che, Zhang et Wang, 2020, by original designation.

Notes. The presence of the peculiar moon-shaped processes of the dorsolateral lobes of the phallobase and the distinct process below the neck of capitulum of style in the species of Tetrichina and Lunatissus (CHAng et al. 2020b, figs 35, 38, ZHANG et al. 2020, figs 222e, 222h, 223e, 223h) leave no doubt about 
the identity of these genera; therefore, their subjective synonymy is hereby proposed. According to the structure of the phallobase Tetrichina is closely related to the monotypical genus Yangissus Chen, Zhang et Chang, 2014 known from Guizhou (CHen et al. 2014), but the latter is well distinguished by the presence of furcate ventral aedeagal hooks (CHEN et al. 2014, fig. 2-82M). The genus Tetrichina is apparently endemic to Hainan Island.

The date of publication of the work of CHANG et al. (2020b) is indicated in the first page of the article as 6th August, 2020. Thus, Tetrichina has priority over Lunatissus.

A comparison of the drawings of the male genitalia of Tetrichina and Lunatissus species in the original publications of CHANG et al. (2020b), WANG et al. (2020), and ZHANG et al. (2020) revealed the synonymies listed below.

\section{Tetrichina fuscovinclum Wang et Bourgoin, 2020}

Tetrichina fuscovinclum Wang et Bourgoin in WANG et al. 2020: 594, figs. 10-24.

Lunatissus brevis Che, Zhang et Wang in Zhang et al. 2020: 497, fig. 222, pl. 39 d-f, syn. n.

Notes. The paper of WANG et al. (2020) was published on the 2nd of October 2020 as indicated on the first page and accordingly T. fuscovinclum has priority over L. brevis. The grammatical gender of the generic name Tetrichina is feminine (CHANG et al. 2020b); the epithet fuscovinclum is to be treated as a noun in apposition, therefore its ending is not to be changed.

\section{Tetrichina trihamulata Chang et Chen, 2020}

Tetrichina trihamulata Chang et Chen in CHANG et al. 2020b: 42, figs 28-48.

Lunatissus longus Che, Zhang et Wang in Zhang et al. 2020: 498, fig. 223, Pl. 39 g-i, syn. n.

Notes. Publication dates are discussed above.

\section{Genus Microsarimodes Chang et Chen, 2019}

Microsarimodes Chang et Chen, 2019 in Chang et al. 2019: 137. Type species: Microsarimodes tumida Chang et Chen, 2019, by original designation.

Eusarimodes Meng, Qin et Wang in ZHAng et al. 2020: 499, syn. n. Type species: Eusarimodes maculosus Che, Zhang et Wang, 2020, by original designation.

Notes. Microsarimodes and its single included species (M. tumida in its original description, here corrected to M. tumidus, because the grammatical gender of Microsarimodes is masculine, cf. ICZN (1999), Art. 30.1.4.4) were not treated by Zhang et al. (2020). The peculiar ventral lobe of the phallobase (narrow basally, but strongly enlarged before apex), the dorsolateral lobes of 
phallobase being provided with large semicircular processes ventrally covering ventral aedeagal hooks, and the massive styles, without neck, but with a comb before capitulum dorsally, clearly illustrated by both author groups (Chang et al. 2019, figs 25, 27, 28; Zhang et al. 2020, figs 224e, 224h, 224i), leave no doubt that the two genera are identical, therefore their subjective synonymy is hereby proposed, resulting in the following new combination:

Microsarimodes maculosus (Che, Zhang et Wang, 2020), comb. n. Eusarimodes maculosus Che, Zhang et Wang in Zhang et al. 2020: 500, fig. 224, Pl. 39 j-1.

\section{Subfamily Hysteropterinae Melichar, 1906}

\section{Genus Celyphoma Emeljanov, 1971}

Celyphoma Emeljanov, 1971: 625. Type species: Hysteropterum fruticulinum Emeljanov, 1964, by original designation.

\section{Celyphoma bifurca Meng et Wang, 2012}

Celyphoma bifurca Meng et Wang, 2012: 25, figs 6-10, 25-35.

Celyphoma gansua Chan, Zhang et Chang, 2014: 129, fig. 2-69, syn. n.

Notes. This species is readily distinguished by the long, apically bifurcate processes of the dorsolateral phallobase lobes (MENG \& WANG 2012, fig. 42, CHAN et al. 2014, fig. 2-69K); there seems to be no difference between C. bifurca and C. gansua, hence their subjective synonymy is proposed.

Acknowledgements - I am glad to thank Prof. Yalin Zhang (Northwest A\&F University, Yangling, China) for his information on publication dates and Dr. Dávid Rédei (National Chung Hsing University, Taichung, Taiwan) and Prof. Dr. Hannelore Hoch (Berlin, Germany) for their review of the manuscript and valuable comments and corrections. My study was supported by the Russian State Research project No. 1021051302540-6.

\section{REFERENCES}

Anufriev, G. A. \& Emeljanov, A. F. (1988): Suborder Cicadinea (Auchenorrhyncha). Pp. 12-495. In: LeR, P. A. (ed.): Opredelitel' nasekomykh Dal'nego Vostoka SSSR, Vol. 2. Nauka, Leningrad. 
Bourgoin, T. \& WANG, M. (2020): Parahiraciini (Hemiptera, Fulgoromorpha, Issidae): one new genus, two new species and three new subtribes. - ZooKeys 997: 69-94. https://doi.org/10.3897/zookeys.997.52857

Chan, M. L. \& YANG, C. T. (1994): Issidae of Taiwan (Homoptera: Fulgoroidea). - National Chung Hsing University, Taichung, 188 pp.

Chang, Z.-M., YAnG, L. \& Chen, X.-S. (2019): A new genus Microsarimodes with one species from Hainan Province in China (Hemiptera: Fulgoromorpha: Issidae). - Zootaxa 4688(1): 135-143. https://doi.org/10.11646/zootaxa.4688.1.8

Chang, Z.-M., YANG, L. \& Chen, X.-S. (2020a): First records of the genera Sivaloka Distant, 1906, with two new species from China, and description of a new species of genus Kodaianella Fennah, 1956 (Hemiptera, Fulgoromorpha, Issidae). - ZooKeys 917: 85104. https://doi.org/10.3897/zookeys.917.47326

Chang, Z.-M., YANG, L. \& Chen, X.-S. (2020b): Two new genera with species of the tribe Sarimini (Hemiptera, Fulgoromorpha, Issidae) from China. - ZooKeys 956: 31-47. https://doi.org/10.3897/zookeys.956.47784

Chen, X.-S., Zhang, Z.-G. \& Chang, Z.-M. (2014): Issidae and Caliscelidae (Hemiptera: Fulgoroidea) from China. - Guizhou Science and Technology Publishing House, Guiyang, $242 \mathrm{pp}$.

Emeljanov, A. F. (1971): New genera of leafhoppers of the families Cixiidae and Issidae (Homoptera, Auchenorrhyncha) from the fauna of the USSR. - Entomologicheskoe Obozrenie 50(3): 619-627. [English translation: Entomological Review 50(3): 350-354 (1971).]

Gnezdilov, V. M. (2013): On the genera Sivaloka Distant, 1906 and Kodaianella Fennah, 1956 (Hemiptera: Fulgoroidea: Issidae). - Deutsche Entomologische Zeitschrift 60(1): 41-44. https://doi.org/10.1002/mmnd.201300004

Gnezdilov, V. M. (2018): Addenda to the revisions of the genera Gergithus Stål and Hemisphaerius Schaum (Hemiptera, Auchenorrhyncha, Fulgoroidea: Issidae). - Entomological Review 97(9): 1338-1352. https://doi.org/10.1134/S0013873817090123

Gnezdilov, V. M. \& Hayashi, M. (2016): New genus of the family Issidae (Hemiptera, Fulgoroidea) from Japan. - Japanese Journal of Systematic Entomology 22(1): 47-49.

Gnezdilov, V. M., Holzinger, W. E. \& Wilson, M. R. (2014): The Western Palaearctic Issidae (Hemiptera, Fulgoroidea): an illustrated checklist and key to genera and subgenera. - Proceedings of the Zoological Institute RAS Vol. 318, Suppl. 1, 124 pp. http://www. zin.ru/journals/trudyzin/doc/vol_318_s1/TZ_318_1_Supplement_Gnezdilov.pdf

Gnezdilov, V. M., Konstantinov, F. V. \& Bodrov, S. Y. (2020): New insights into the molecular phylogeny and taxonomy of the family Issidae (Hemiptera: Auchenorrhyncha: Fulgoroidea). - Proceedings of the Zoological Institute RAS 324(1): 146-161. https://doi.org/10.31610/trudyzin/2020.324.1.146

ICZN (1999): International Code of Zoological Nomenclature. Fourth edition. - International Trust for Zoological Nomenclature, London, $306 \mathrm{pp}$.

Melichar, L. (1906): Monographie der Issiden (Homoptera). - Abhandlungen der K. K. zoologisch-botanischen Gesellschaft in Wien 3(4): 1-327.

Meng, R. \& Wang, Y. (2012): Two new species of the genus Celyphoma Emeljanov, 1971 (Hemiptera: Fulgoromorpha: Issidae) from China. - Zootaxa 3497: 17-28.

https://doi.org/10.11646/zootaxa.3497.1.2 
Wang, M., Zhang, Y. \& Bourgoin, T. (2020): Notes on genera of Sarimini with description of two new species in the genera Microsarimodes and Tetrichina (Hemiptera: Fulgoromorpha: Issidae). - Zootaxa 4858(4): 589-600. https://doi.org/10.11646/zootaxa.4858.4.7

Zhang, Y., Che Y., Meng, R. \& Wang, Y. (2020): Hemiptera. Caliscelidae. Issidae. Insecta. Vol. 70. Fauna Sinica. - Science Press, Beijing, 655 pp. +43 photo plates.

Received September 2, 2021, accepted January 24, 2022, published February 14, 2022 